\title{
Development of methods for calculating non-stationary heat transfer between multilayer structures
}

\author{
A. Gorshkov \\ Saint Petersburg State University of Industrial Technologies and Design, Saint Petersburg, Russia
}

A. Demidov

Rector, Saint Petersburg State University of Industrial Technologies and Design, Saint Petersburg, Russia

A. Makarov

Vice-Rector of Science, Saint Petersburg State University of Industrial Technologies and Design, Saint

Petersburg, Russia

\begin{abstract}
When solving various problems of heat transfer between multilayer structures separating physical media with different temperature characteristics, various heat exchangers or devices are used (Gorshkov et al., 2018; Korniyenko et al., 2016; Gorshkov et al., 2015). Examples of heat exchange devices may include a heater and various heat utilization appliances. In real operating conditions of multilayer structures separating media with different temperatures, the heat transfer behaviour through their boundaries is almost always unsteady (Gorshkov et al., 2014; Grinfeldi et al., 2014; Vatin et al., 2014). However, for the overwhelming majority of practical problems, as a rule, a quasi-stationary heat transfer mode is considered, characterized by the time constancy of the heat flux through the structure. The quasi-stationary heat transfer mode can only be established in very short time intervals. The convenience of such a mode of heat transfer is stipulated by the fact that when considering it, all thermotechnical calculations that are used in design practice are greatly simplified (Gorshkov et al., 2013a; Gorshkov et al., 2013b; Zimin et al., 2013). Unsteady heat transfer also occurs when solving problems of heating and cooling objects, damping temperature fluctuations in structures and some others. However, their practical use is often happens to be limited.
\end{abstract}

\section{INTRODUCTION}

To solve a number of practical problems of heat transfer between multilayer structures separating physical media with different temperature characteristics, the existing calculation methods have a number of significant inconveniences. For example, when considering a structure of several layers, differing in temperature characteristics, in order to determine the temperature fields at each boundary of the corresponding layer, it becomes necessary to merge solutions, which leads to unnecessary complication of calculations (Gorshkov et al., 2013c; Romanova et al., 2007; Romanova et al., 2005a). Moreover, the direct input from each layer is often far from obvious. There are also known problems with the setting of boundary conditions, and the constructions of some formulas when solving problems of unsteady heat transfer are so voluminous that their use for engineering calculations is difficult (Romanova et al., 2005b; Perevoznikov et al., 2004; Gorshkov et al., 2003). In the stationary mode of heat transfer, the equations and calculation methods are greatly simplified, however the reserves of energy saving when considering them, especially when considering multilayer rather massive material structures, are largely exhausted. In this respect at the present stage of the development of constructional thermal physics, reserves of energy savings should be sought with considering 
engineering problems in the non-stationary heat transfer mode (Makarov et al., 2015). Therefore, the search for optimal solutions with considering modes of non-stationary heat transfer is relevant when creating engineering calculation methods. The authors propose a description of the processes of heat transfer through multilayer structures in a non-stationary mode in the terms of the transport theory (Makarov et al., 2016).

\section{DEVELOPMENT OF A METHODOLOGY FOR SOLVING PROBLEMS OF NON-STATIONARY HEAT TRANSFER}

The process of heat transfer from the standpoint of the theory of transport can be considered as the diffusion of an additive scalar property - thermal energy. Let the heat transfer be carried out along some axis Ox. Since thermal energy propagates both along and against the Ox axis, it is expedient to introduce the corresponding heat flow densities $q_{\leftrightarrow}(x, t)$ as a local characteristic which can be considered as vectors in two-dimensional space As one of the local characteristics of the medium we can introduce the rate of propagation of thermal energy c (x) (Pereborova et al., 2018e; Makarov et al., 2018a; Pereborova et al., 2019).

It is obvious that the heat current density $-q(x, t)=q_{\rightarrow}(x, t)+q \quad(x, t)$. The transferred part of the internal energy can be interpreted as a nonequilibrium phonon gas, diffusing in a general way by different mechanisms. The density of the transferred part of the energy $U(x, t)=1 / c \cdot\left[q_{\rightarrow}(x, t)+q(x, t)\right]$. Moreover, it can be assumed that $U=c_{\nu} \rho T$ where $c_{v}-$ specific heat, $\rho$ - local density of the medium, $T(x, t)$ - desired temperature field $\left(d U=c_{\nu} \rho d T\right) \leftarrow$ (Demidov et al., 2006a; Demidov et al., 2006b; Demidov et al., 2007a).

From the general view of the theory of transport, the spread of the additive property is determined not only by the property itself, but also by the properties of one-dimensional space, which we will call the medium. The characteristics of the medium can be determined by the distribution of other properties (for example, moisture transfer, mechanical loads, etc.), and they can also depend (in the general case, nonlinearly) on the distribution of the studied property itself (thermal energy) (Stalevich et al., 2003; Makarov et al., 2002; Stalevich et al., 2002a).

Let us consider a section of the Ox axis - $\left[x_{1} ; x_{2}\right]$, which we will call a layer of the medium. Let us assume that a heat current $\left[x_{1} ; x_{2}\right]$ "falls" on the layer $q_{0}\left(x_{1}-0, t\right)$. First we consider the case when $q_{0}=\delta\left(t^{\prime}-t\right)$, where $t^{\prime}$ - current time, $t$ - fixed point in time. Let us introduce the following characteristics of the medium layer (Stalevich et al., 2002b; Stalevich et al., 2000):

- transmission coefficient $-\Lambda\left(t, x_{1} \mid x_{2}, \tau\right)=q_{\rightarrow}\left(x_{2}-0, t+\tau\right)$ - heat current density passing through the layer $\left(x_{1} ; x_{2}\right)$ in time $\tau$; it is being understood that outside the boundaries of the layer $\left[x_{1} ; x_{2}\right]$ there are screens completely absorbing heat;

- reflection coefficient - $\mathrm{P}\left(t, x_{1} \mid x_{2}, \tau\right)=q\left(x_{1}+0, t+\tau\right)$ - the density of the heat current reflected from the layer $\left(x_{1} ; x_{2}\right)$ in time $\tau$; i.e, the first reflection without a preceding crossing boundaries $x=x_{1}$ and $x=x_{2}$ earlier;

- absorption coefficient - $R\left(t, x_{1} \mid x_{2}, \tau\right)$ - heat current absorbed (born) in the layer $\left(x_{1} ; x_{2}\right)$ in time $(t+\tau)$.

Note that the introduced coefficients and the currents themselves $q_{\leftrightarrow}$ will be considered complex numbers (in terms of multichannel theory the coefficients $\Lambda, P, R$ will be square matrices). The absorption coefficient $R$ introduced above does not imply that there are permanent sources (leaks) of heat in the medium. By the heat source we understand the generation of heat energy $U$ at the moment $t>t_{0}$, if it was absent before, and the interval is completely limited by screens. The introduction of the properties of absorbing, reflecting, semitransparent screens has a simple meaning and serves only as a way of visual description (Pereborova et al., 2020a).

All coefficients (distributions) $\Lambda, \mathrm{P}, R$ are assumed to be zero for $\tau \prec 0$ (principle of causality). For distributions $\Lambda, \mathrm{P}, R$ we can compose recurrence relations.

In the most general case in terms of the ring $R_{\bar{\otimes}}[4]$ these relations have the form: 


$$
\begin{aligned}
& \Lambda\left(x_{1} \mid x_{3}\right)=\Lambda\left(x_{1} \mid x_{2}\right) \bar{\otimes}\left[\delta-\mathbf{P}\left(x_{2} \mid x_{3}\right) \bar{\otimes} \mathbf{P}\left(x_{2} \mid x_{1}\right)\right]^{\bar{\otimes}-1} \bar{\otimes} \Lambda\left(x_{2} \mid x_{3}\right) \\
& \mathbf{P}\left(x_{1} \mid x_{3}\right)=\mathbf{P}\left(x_{1} \mid x_{2}\right)+\Lambda\left(x_{1} \mid x_{2}\right) \bar{\otimes}\left[\delta-\mathbf{P}\left(x_{2} \mid x_{3}\right) \bar{\otimes} \mathbf{P}\left(x_{2} \mid x_{1}\right)\right]^{\bar{\otimes}-1} \bar{\otimes} \mathbf{P}\left(x_{2} \mid x_{3}\right) \bar{\otimes} \Lambda\left(x_{2} \mid x_{1}\right), \\
& R\left(x_{1} \mid x_{3}\right)=R\left(x_{1} \mid x_{2}\right)+\Lambda\left(x_{1} \mid x_{2}\right) \bar{\otimes}\left[\delta-\mathbf{P}\left(x_{2} \mid x_{3}\right) \otimes \mathbf{P}\left(x_{2} \mid x_{1}\right)\right]^{\otimes-1} \bar{\otimes} \\
& \bar{\otimes}\left[\mathbf{P}\left(x_{2} \mid x_{3}\right) \otimes R\left(x_{2} \mid x_{1}\right)+R\left(x_{2} \mid x_{3}\right)\right]
\end{aligned}
$$

The mathematical apparatus is based on non-commutative multiplication. To clarify the introduced symbols let us consider the set of functions $C_{t, \tau}$ of two real variables $t$ and $\tau$, which are definite and piecewise continuous for $\tau \geq 0$ and analytic with respect to the variable $t \in(-\infty ;+\infty)$ (Pereborova et al., 2020b).

Let $a(t, \tau), b(t, \tau), c(t, \tau) \in C_{t, \tau}$ Let us define the product of functions in the form:

$$
c(t, \tau)=a(t, \tau) \bar{\otimes} b(t, \tau) \stackrel{D e f}{=} \int_{0}^{\tau} a\left(t, \tau_{1}\right) b\left(t+\tau_{1}, \tau-\tau_{1}\right) d \tau_{1}
$$

Let us denote $R_{\bar{\otimes}}$ - the ring of functions $C_{t, \tau}$ with natural definite addition and multiplication in the sense of (2).

Let us see an ordered sequence of functions $a, b, c \ldots \in R_{\bar{\Phi}}$. In some problems $a(t, \tau)$ can be interpreted as a distribution function of some event $A$, that started at time $\mathrm{t}$ and distributed over the duration of the event $\tau \geq 0$. In this case, we will call the above sequence of functions a process consisting of sequential execution of events $A, B, C, \ldots$

The need to use a ring $R_{\bar{\otimes}}$ means that most of the natural phenomena around us are some ordered chains of certain events (Pereborova et al., 2020c).

In the simplest case if $a, b, c, \ldots$ do not depend on a variable $t$ expressly (for example, the start time of an event), then integral (2) represents the usual convolution of functions, i.e. $c(\tau)=a(\tau) * b(\tau)$. Consequently, $R_{*} \subset R_{\bar{\otimes}}$. To describe specific processes, it is more convenient to use not the ring $R_{\bar{\otimes}}$, itself, but the ring $R_{\bar{\otimes}}$. Isomorphism between $\operatorname{rings} R_{\bar{\otimes}}$ and $R_{\bar{\otimes}}$ is determined using the Laplace transformation

$$
A(t, S)=\int_{0}^{\infty} a(t, \tau) e^{-S \tau} d \tau
$$

where $A(t, S)$ - analytic function in both variables (real $t$ and complex $S$ ) (Pereborova et al., 2020d).

We define the product of functions $A(t, S) \otimes B(t, S)=C(t, S) ; A, B, C \in R_{\otimes}$, describing the multiplicative semigroup of the ring $R_{\otimes}$ as follows:

$$
C(t, S) \stackrel{\text { Def }}{=} \sum_{n=0}^{\infty} \frac{(-1)^{n}}{n !} \cdot \frac{\partial^{n} A(t, S)}{\partial S^{n}} \cdot \frac{\partial^{n} B(t, S)}{\partial t^{n}}=A(t, S) \otimes B(t, S)
$$

The associativity of the ring $R_{\otimes}$ follows from the associativity of the ring $R_{\bar{\otimes}}$. Multiplication in the sense of (3) is associated with addition due to the laws of distributivity. $R_{\otimes}$ - a ring with a unit element, while the unit element of the ring $R_{\otimes}$ is the function $E(t, S) \equiv 1$.

We will consider the physical meaning of equations (1) using the example of the first equation of this system. Event - the passage of a heat carrier (phonon) through the layer $\left[x_{1} ; x_{3}\right]$ is possible only by crossing the imaginary boundary an odd number of times (Pereborova et al., 2018a).

Then, according to theorems on addition and multiplication of probabilities for distributions, we have 


$$
\begin{aligned}
& \Lambda\left(t, x_{1} \mid x_{2}, \tau\right)=\int_{0}^{\tau} \Lambda\left(t, x_{1} \mid x_{2}, \tau_{1}\right) \cdot \Lambda\left(t+\tau_{1}, x_{2} \mid x_{3}, \tau-\tau_{1}\right)+ \\
& +\Lambda\left(x_{1} \mid x_{2}\right) \bar{\otimes} \mathbf{P}\left(x_{2} \mid x_{3}\right) \bar{\otimes} \mathbf{P}\left(x_{2} \mid x_{1}\right) \bar{\otimes} \Lambda\left(x_{2} \mid x_{3}\right)+\ldots= \\
& =\Lambda\left(x_{1} \mid x_{2}\right) \bar{\otimes}\left[\delta-\mathbf{P}\left(x_{2} \mid x_{3}\right) \bar{\otimes} \mathbf{P}\left(x_{2} \mid x_{1}\right)\right]^{\bar{\otimes}-1} \bar{\otimes} \Lambda\left(x_{2} \mid x_{3}\right)
\end{aligned}
$$

Instead of distributing $\Lambda, \mathrm{P}, R$ it is advisable to immediately use their Laplace images, that is $\bar{\Lambda}, \overline{\mathrm{P}}, \bar{R}$. In this case, instead of the symbol $\bar{\otimes}$ it is necessary to use multiplication $\otimes$ in the sense of (4) (Makarov et al., 2018b).

The theory of transfer formulates the transition from one ring to another in the form of the "non-stationary principle". The essence of it is as follows. Let some additive quantity $M$, that has no structure be described by coefficients $\bar{\Lambda}, \overline{\mathrm{P}}, \bar{R}$, and one with a structure - by analogous elements $\widetilde{\Lambda}, \widetilde{\mathrm{P}}, \widetilde{R}$, while $\widetilde{\Lambda}, \widetilde{\mathrm{P}}, \widetilde{R}$ belong to a more complex ring $R_{0}$. Then the transition from the description of the propagation of the property $M$ to the description of the propagation of the property $\widetilde{M}$ is reduced to replacing the operation $\otimes$ with the operation of multiplication and replacing 1 by the unit element of the ring $R_{0}$ without changing the form of equations (Pereborova et al., 2019a; Pereborova et al., 2018b; Makarov et al., 2014a). In other words, system (1) is also valid for the multichannel case with the corresponding substitution of symbols.

Accordingly, in a general way, system (1) will take the form:

$$
\begin{aligned}
& \bar{\Lambda}\left(x_{1}, t \mid x_{3}, S\right)=\bar{\Lambda}\left(x_{1} \mid x_{2}\right) \otimes\left[I-\overline{\mathrm{P}}\left(x_{2} \mid x_{3}\right) \otimes \overline{\mathrm{P}}\left(x_{2} \mid x_{1}\right)\right]^{\otimes-1} \otimes \widetilde{\Lambda}\left(x_{2} \mid x_{3}\right) \\
& \overline{\mathrm{P}}\left(x_{1}, t \mid x_{3}, S\right)=\overline{\mathrm{P}}\left(x_{1} \mid x_{2}\right)+\bar{\Lambda}\left(x_{1} \mid x_{2}\right) \otimes\left[I-\overline{\mathrm{P}}\left(x_{2} \mid x_{3}\right) \overline{\mathrm{P}}\left(x_{2} \mid x_{1}\right)\right]^{\otimes-1} \otimes \\
& \otimes \overline{\mathrm{P}}\left(x_{2} \mid x_{3}\right) \otimes \Lambda\left(x_{2} \mid x_{1}\right) \\
& \bar{R}\left(x_{1}, t \mid x_{3}, S\right)=\bar{R}\left(x_{1} \mid x_{2}\right)+\bar{\Lambda}\left(x_{1} \mid x_{2}\right) \otimes\left[I-\overline{\mathrm{P}}\left(x_{2} \mid x_{3}\right) \otimes \overline{\mathrm{P}}\left(x_{2} \mid x_{1}\right)\right]^{\otimes-1} \otimes \\
& \otimes\left[\overline{\mathrm{P}}\left(x_{2} \mid x_{3}\right) \otimes \bar{R}\left(x_{2} \mid x_{1}\right)+\bar{R}\left(x_{2} \mid x_{3}\right)\right]
\end{aligned}
$$

The relations (6) make it possible to successively determine the properties of a system of layers, with knowing the properties of each layer, i.e. give a constructive way to solve the problems of heat transfer (Demidov et al., 2006c).

The non-commutativity of the rings $R_{\bar{\otimes}}$ and $R_{\otimes}$ is essential for strongly non-stationary processes, when the properties of the medium change over the mean time of heat passage, i.e., each time the "wandering" phonon enters a new medium. If all the coefficients do not depend on time $t$ explicitly or this dependence can be neglected, then the multiplication " $\otimes$ " is an ordinary multiplication, i.e.

$$
\begin{aligned}
\bar{\Lambda}\left(x_{1} \mid x_{3}, S\right) & =\frac{\bar{\Lambda}\left(x_{1} \mid x_{2}\right) \bar{\Lambda}\left(x_{2} \mid x_{3}\right)}{1-\overline{\mathrm{P}}\left(x_{2} \mid x_{3}\right) \overline{\mathrm{P}}\left(x_{2} \mid x_{1}\right)} \\
\overline{\mathrm{P}}\left(x_{1} \mid x_{3}, S\right) & =\overline{\mathrm{P}}\left(x_{1} \mid x_{2}\right)+\frac{\bar{\Lambda}\left(x_{1} \mid x_{2}\right) \bar{\Lambda}\left(x_{2} \mid x_{1}\right) \overline{\mathrm{P}}\left(x_{2} \mid x_{3}\right)}{1-\overline{\mathrm{P}}\left(x_{2} \mid x_{3}\right) \overline{\mathrm{P}}\left(x_{2} \mid x_{1}\right)} \\
\bar{R}\left(x_{1} \mid x_{3}, S\right) & =\bar{R}\left(x_{1} \mid x_{2}\right)+\frac{\bar{\Lambda}\left(x_{1} \mid x_{2}\right)\left[\overline{\mathrm{P}}\left(x_{2} \mid x_{3}\right) \bar{R}\left(x_{2} \mid x_{1}\right)+\bar{R}\left(x_{2} \mid x_{3}\right)\right]}{1-\overline{\mathrm{P}}\left(x_{2} \mid x_{3}\right) \overline{\mathrm{P}}\left(x_{2} \mid x_{1}\right)}
\end{aligned}
$$

Non-commutativity is also essential in those cases when the medium is inhomogeneous or there are inclusions in the medium layer. In this case, it is necessary to introduce the concept of a propagation channel and all coefficients $\bar{\Lambda}, \overline{\mathrm{P}}, \bar{R}$ are square matrices. In reality, Fourier's law is rather approximate and functions well only for the stationary case. This is explained by the fact that heat transfer even in a homogeneous medium does not follow just one mechanism (there are also internal heat transfer channels) (Rymkevich et al., 2013). 
The existence of several mechanisms of heat conduction leads to a slightly different system of equations describing the process of heat transfer (Pereborova et al., 2019b; Pereborova et al., 2018c; Pereborova et al., 2018d).

For the majority of engineering calculations all these "subtleties" may be disregarded and the above relations (7) can be used.

The described method of heat transfer makes it possible to establish correlations between energy densities (i.e., temperature) and heat currents at different points in space. Indeed, let us consider the two-point identity for heat fluxes. Given $x=x_{1}$ we know the heat currents $q_{1 \leftrightarrow}(S)$ Let us define these heat currents at an arbitrary point $x_{2}$ (for greater certainty let it be $\left.x_{2}>x_{1}\right)$.

Using the developed method, we have:

$$
\begin{aligned}
& \overline{q_{\rightarrow}}\left(x_{2} \mid S\right)=\left[\underset{\rightarrow}{\overline{q_{0}}}+\underset{\leftarrow}{q_{0}} \otimes \overline{\mathrm{P}}\left(x_{1} \mid-\infty\right)\right] \otimes\left[I-\overline{\mathrm{P}}\left(x_{1} \mid+\infty\right) \otimes \overline{\mathrm{P}}\left(x_{1} \mid-\infty\right)\right]^{\otimes-1} \otimes \\
& \otimes \bar{\Lambda}\left(x_{1} \mid x_{2}\right) \otimes\left[I-\overline{\mathrm{P}}\left(x_{2} \mid+\infty\right) \otimes \overline{\mathrm{P}}\left(x_{2} \mid x_{1}\right)\right]^{\otimes-1}, \\
& \overline{q_{\rightarrow}}\left(x_{2} \mid S\right)=\overline{q_{\rightarrow}}\left(x_{2} \mid S\right) \otimes \overline{\mathbf{P}}\left(x_{2} \mid+\infty\right)
\end{aligned}
$$

It is not difficult to express currents $q_{1}$ by means of $q_{2}$. In particular, with $x_{2}=x_{1}=x$ we obtain a true identity that connects $\bar{\Lambda}$ and $\overline{\mathrm{P}}$ with each other. In general, by splitting a certain layer in different ways, we can get useful results, sometimes greatly simplifying the solution of specific problems. Thus, the property currents at one point in one-dimensional space completely determine the property currents for all other points. The method of accounting for multiple border crossings can be generalized to the three-dimensional case (Makarov et al., 2017b).

For continuous space, it is advisable to consider an infinitely thin layer $d x$. We have $\bar{\Lambda}(x \mid x) \equiv 1, \overline{\mathrm{P}}(x \mid x)=\bar{R}(x \mid x) \equiv 0$, if there are no singularities (the existing singularities will be called screens). Expanding $\overline{\mathrm{P}}(x \mid x \pm d x)$ and $\bar{R}(x \mid x \pm d x) d x>0$ in a series and leaving the first terms of the expansion, we will have:

$$
\begin{aligned}
& \overline{\mathrm{P}}(x \mid x \pm d x)=a(x, t) d x+0(d x) \\
& \bar{R}(x \mid x \pm d x)=\chi(x, t) d x+0(d x)
\end{aligned}
$$

where $a(*, t)$ and $\chi(*, t)$ will be called reflection and absorption indices respectively. Thus, $a$ and $\chi$ are the local characteristics of the medium in relation to the propagation of heat (Demidov et al., 2017).

Let us introduce the notion of the average time for the passage of heat by the layer $\Delta x$ as follows:

$$
t_{\lambda} \Delta x \stackrel{D e f}{=}-\frac{\partial}{\partial S}[\ln \bar{\Lambda}(x \mid x+\Delta x)]_{S=0}
$$

For a homogeneous medium $\bar{\Lambda}, \overline{\mathrm{P}}, \bar{R}$ have a simple form:

$$
\begin{aligned}
\bar{\Lambda}(z, S) & =\frac{2 \mu(S-\mu) e^{-\mu z}}{a^{2}-(S-\mu)^{2} e^{-2 \mu z}}, \infty \\
\overline{\mathrm{P}}(z, S) & =\frac{a(S-\mu)\left[1-e^{-2 \mu \mathrm{z}}\right]}{a^{2}-(S-\mu)^{2} e^{-2 \mu \mathrm{z}}}, \\
\bar{R}(z, S) & =\frac{\sqrt{2} \chi \sqrt{S-\mu}}{\sqrt{S-a}} \cdot \frac{\left[1-e^{-\mu \mathrm{z}}\right]}{\left[a+(S-\mu) e^{-\mu \mathrm{z}}\right]}
\end{aligned}
$$


Here we introduce the symbols $z=x_{2}-x_{1}, \quad \mu=\sqrt{\widetilde{S}^{2}-a^{2}}, \quad \widetilde{S}=\frac{S}{c}+(a+\chi)$.

\section{NON-STATIONARY HEAT TRANSFER THROUGH MULTILAYER TEXTILES}

One of the problems that arises when solving problems of unsteady heat transfer through multilayer textiles is the correct setting of the boundary conditions at the media interface. Another problem is limiting the rate of transfer of thermal energy, that is, heat is transferred with some delay (Makarov et al., 2017b). The calculations of the delay in heat transfer between textiles lead to equations of the form:

$$
\begin{aligned}
& \tau_{\mathrm{P}} \frac{\partial \vec{q}}{\partial t}+\vec{q}=-\lambda \vec{\nabla} \vec{T} \\
& \tau_{\mathrm{P}} \frac{\partial^{2} T}{\partial t^{2}}+\frac{\partial T}{\partial t}=\operatorname{div}\left[a_{T} \operatorname{grad} T\right]
\end{aligned}
$$

Here $T(x, y, z, t)$ - is the required temperature field; $\vec{q}$ - heat flux density; $\lambda$ - coefficient of thermal conductivity, $a_{T}=\frac{\lambda}{c_{V} \rho}$ - coefficient of heat diffusion (coefficient of thermal diffusivity); $c_{V}$ and $\rho$ accordingly, the specific heat and density of the material; $\tau_{\mathrm{P}}$ - relaxation time. The equations (12) characterize most of the heat transfer phenomena between textiles. Nevertheless, theoretical estimates show that the relaxation time $\tau_{\mathrm{P}}$ for most textile materials is very short, although the empirically introduced $\tau_{\mathrm{P}}$ corrects non-stationary thermal fields (Makarov et al., 2015a).

The polymeric materials that the studied textiles are composed of have a heterogeneous structure. However, even for a homogeneous medium, there is more than one heat transfer mechanism. The transferred part of the internal energy can be interpreted as a nonequilibrium phonon gas diffusing in the general case by different mechanisms (longitudinal and transverse waves) (Makarov et al., 2015b).

The process of transferring heat between textiles can be viewed as the diffusion of an additive scalar property - thermal energy with an internal structure.

Let us assume that heat energy propagates through $N$ various mechanisms, which we will call heat propagation channels. It is the amount of heat energy on each channel that determines the structure of the heat flow. The transferred part of the internal energy $U(x, t)$ is equal to the sum of the energies on each channel (internal energy reservoirs) (Demidov et al., 2009).

$$
U(x, t)=\sum_{n=1}^{N} \frac{1}{c_{n}}\left[q_{\vec{n}}(x, t)+q_{\overleftarrow{n}}(x, t)\right]=\sum_{n=1}^{N}\left[U_{\vec{n}}(x, t)+U_{\overleftarrow{n}}(x, t)\right]
$$

It should be noted that $T(x, t)$ - some average temperature over a physically small volume. Since the transfer of heat is an irreversible and nonequilibrium process, it is more accurate to talk about the local temperature on each channel (the principle of local equilibrium). Therefore, in the case of non-stationary heat transfer, two physical processes take place: the first is the transfer of energy from a more heated body to a less heated one; the second is the exchange of energy between different distribution channels, i.e. relaxation processes. Part of the electromagnetic energy is absorbed according to the well-known exponential Bouguer law, i.e. passes to other channels of heat propagation (Makarov et al., 2014b).

The heat flux density $q(x, t)$ is

$$
q(x, t)=\sum_{n=1}^{N} q_{n}(x, t)=\sum_{n=1}^{N}\left[q_{\vec{n}}(x, t)-q_{\vec{n}}(x, t)\right]
$$


To derive the heat transfer equations generally it is sufficient to write $2 \mathrm{~N}$ equations of continuity for the linear energy density on each channel in accordance with the law of conservation of energy (Demidov et al., 2007a).

Thereat we will have

$$
\begin{aligned}
& \frac{\partial U_{\vec{n}}(x, t)}{\partial t}=-\frac{\partial}{\partial x}\left[U_{\vec{n}}(x, t) c_{n}\right]-\sum_{k=1}^{N}\left[\tilde{a}_{\overrightarrow{n k}}+\tilde{b}_{\overrightarrow{n k}}\right] U_{\vec{n}}(x, t)+\sum_{k=1}^{N} \tilde{a}_{\leftarrow n} U_{\leftarrow}(x, t)+\sum_{k=1}^{N} \tilde{b}_{\vec{k}} U_{\vec{k}}(x, t)
\end{aligned}
$$

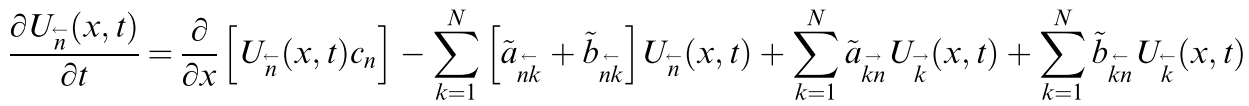

Here $\widetilde{a}_{n k}(x, t) \leftarrow$ is the reflection rate constant, i.e. the share of thermal energy per unit oftime that has passed from channel $n$ to channel $k$ with a change in the direction of propagation; $\widetilde{a}_{n k}(x, t)=\frac{\widetilde{a}_{n k}}{c_{n}}$ - is called the matrix element of the heat flux dissipation indicators; $\widetilde{b}_{n k}(x, t)$ - matrix of constants of transition rate from channel $n$ to channel number $k$, i.e. the proportion of thermal energy per unit of time $\left(\widetilde{q}_{n k} \equiv 0\right)$, that has passed from channel number $n$ to channel number $k$ without changing the direction of movement; the quantity $\left(\widetilde{\theta}_{n k}=\frac{\widetilde{b}_{n k}}{c_{n}}\right.$ is called the matrix element of the transition indicators (Demidov et al., 2007b).

The system equations express the law of conservation of energy transfer with taking into account the internal exchange between the channels. The distribution channel can also be understood as a homogeneous part of a heterogeneous system. In the absence of asymmetry: i.e. without the presence of external fields, fluxes of quantities of the same nature,

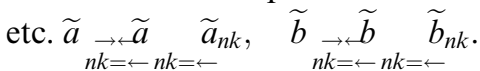

We restrict ourselves to considering the case of a quasi-homogeneous medium whose properties do not change with time (for example, aging). Such a medium will be described by the following constants: $\widetilde{a}_{n k}-N^{2}$ - quantities, $\widetilde{b}_{n k}-N(N-1)$ quantities and $c_{n}-N$ - quantities, i.e. totally $2 N^{2}$ material characteristics. In reality there are much less of them due to the presence of equilibrium equations (Demidov et al., 2006d).

Let us rewrite system (6) in a slightly different form, adding and subtracting the equations of the system term by term, introducing the matrix elements

$$
\begin{aligned}
\theta_{k n} & =\frac{1}{c_{n}} \sum_{n=1}^{N}\left[\tilde{a}_{k n}+\tilde{b}_{k n}\right] \delta_{k n}+\frac{1}{c_{k}}\left[\tilde{a}_{k n}-\tilde{b}_{k n}\right] \\
G_{k n} & =\sum_{m=1}^{\infty}\left[\tilde{a}_{k m}+\tilde{b}_{k m}\right] \delta_{k n}-\left[\tilde{a}_{k n}+\tilde{b}_{k n}\right]
\end{aligned}
$$

In this case, system (5) will be rewritten as follows:

$$
\begin{aligned}
& \frac{\partial U_{n}}{\partial t}+\frac{\partial q_{n}}{\partial x}+\sum_{k=1}^{N} U_{k} G_{k n}=0 \\
& \frac{1}{c_{n}} \frac{\partial q_{n}}{\partial t}+c_{n} \frac{\partial U_{n}}{\partial x}+\sum_{k=1}^{N} q_{k} \theta_{k n}=0
\end{aligned}
$$

The first $N$ of equations are equations of continuity with internal energy transfers from channel to channel. The second $N$ of equations express the generalized Fourier law. From the system of equations $N=1$ hyperbolic heat conductivity equations follow (12) (Leusheva et al., 2019). 
If the thickness of the medium layer is sufficiently large, then in the stationary case (steady state) the Fourier law is fulfilled, i.e.

$$
\begin{aligned}
& \sum_{k=1}^{N} U_{k}^{p} G_{k n}=0 \\
& c_{n} \frac{\partial U_{k}^{p}}{\partial x}+\sum_{k=1}^{N} q_{k}^{p} \theta_{k n}=0
\end{aligned}
$$

The index " $p$ " means that equilibrium has been established between the channels and the principle of local equilibrium is in effect, i.e. the system has a local temperature $T(x)$ and other local characteristics. Let $\omega_{k}^{p}$ - is the fraction of thermal energy propagating through the channel number $n\left(\sum_{n=1}^{N} \omega_{k}^{p}=1\right)$, then the system (Nikolaev et al., 2018)

$$
\begin{aligned}
& \sum_{k=1}^{N} \omega_{k}^{p} G_{k n}=0 \\
& \sum_{n=1}^{N} \omega_{k}^{p}=1
\end{aligned}
$$

uniquely determines the value $\omega_{k}^{p}$ (Lapshin, 2014).

In addition, for such a stationary quasi-equilibrium, the principle of detailed equilibrium can be applied - the amount of energy passing from channel number $k$ to channel $n$ is equal to the amount of energy passing from channel $n$ to channel number $k$.

This way

$$
\begin{aligned}
& \omega_{k}^{p} \tilde{a}_{k n}=\omega_{n}^{p} \tilde{a}_{n k} \\
& \omega_{k}^{p} \tilde{b}_{k n}=\omega_{n}^{p} \tilde{b}_{n k}
\end{aligned}
$$

that significantly reduces the number of linearly independent characteristics of the environment. In particular, for the stationary case, we have the following equality:

$$
\frac{1}{a_{T}} c_{n} \omega_{n}^{p}-\omega_{k}^{p} \theta_{k n}=0
$$

With additional $\mathrm{N}$ - constraint equations (Gryazev et al., 2017)

\section{CONCLUSION}

As a result, a mathematical model has been developed for calculating multilayer structures in the non-stationary heat transfer mode. In engineering problems, when assessing the energy saving potential, equations and models obtained in a stationary heat transfer mode are usually considered. The reserves of thermal energy savings for them are well studied, and their potential at the present stage of development of science in the area of knowledge under consideration is largely realized. In this regard, an additional potential for energy saving can be identified when considering the heat transfer process in a nonstationary mode.

The developed mathematical model is based on the methods of the general transport theory. An equation is obtained to determine the difference in the average transit times of a heat flux through a multilayer structure that separates media with different temperatures for 
a different sequence of layers arrangements. The influence of the order of the layers on its thermal stability is shown. An expression is obtained that shows the difference in the average transit times of a heat flux through a multilayer structure with different arrangements of its layers. The obtained equations can be used, inter alia, when describing the process of heat transfer through multilayer textiles.

\section{FUTURE RESEARCH AND ACKNOWLEDGEMENTS}

The study was funded within the framework of the state assignment of the Ministry of Science and Higher Education of the Russian Federation, Project No. FSEZ-2020-0005.

\section{REFERENCES}

Demidov, A.V., Makarov, A.G., Stalevich, A.M. (2006a) Methods of computer analysis of viscoelasticity of technical materials. Izvestiya Vysshikh Uchebnykh Zavedenii, Seriya Teknologiya Tekstil'noi Promyshlennosti, Vol. 291, No 3, pp. 13-17. eid=2-s2.0-37849188658

Demidov, A.V., Makarov, A.G., Stalevich, A.M. (2006b) Definition of the mechanical characteristics of textile stuffs at variable temperature. Izvestiya Vysshikh Uchebnykh Zavedenii, Seriya Teknologiya Tekstil'noi Promyshlennosti, Vol. 291, No 3, pp. 13-17. eid=2-s2.0-37849188658

Demidov, A.V., Makarov, A.G., Stalevich, A.M. (2006c) The criteria of optimal selection of mathematical model of textile materials viscoelasticity. Izvestiya Vysshikh Uchebnykh Zavedenii, Seriya Teknologiya Tekstil'noi Promyshlennosti, Vol. 293, No 5, pp. 21-25. eid=2-s2.0-34247548784

Demidov, A.V., Makarov, A.G., Stalevich, A.M., Petrova, L.N., Chelishev, A.M. (2006d) Research of changes of deformation properties of polyester threads depending on twist amount. Izvestiya Vysshikh Uchebnykh Zavedenii, Seriya Teknologiya Tekstil'noi Promyshlennosti, Vol. 292, No 4, pp. 9-13. eid=2-s2.0-33845499474

Demidov, A.V., Makarov, A.G., Stalevich, A.M. (2007a) Definition of the computer forecasting trends of deformation properties of textile stuffs. Izvestiya Vysshikh Uchebnykh Zavedenii, Seriya Teknologiya Tekstil'noi Promyshlennosti, Vol. 297, No 2, pp. 14-17. eid=2-s2.0-38849203122

Demidov, A.V., Makarov, A.G., Stalevich, A.M. (2007b) Predicting the nonlinear hereditary viscoelasticity of polymers. Journal of Applied Mechanics and Technical Physics, Vol. 48, No 6, pp. 897-904. DOI: $10.1007 / \mathrm{s} 10808-007-0114-8$

Demidov, A.V., Makarov, A.G., Stalevich, A.M. (2007c) System analysis of viscoelasticity of textile stuffs. Izvestiya Vysshikh Uchebnykh Zavedenii, Seriya Teknologiya Tekstil'noi Promyshlennosti, Vol. 298, No 3, pp. 11-14. eid=2-s2.0-34648822922

Demidov, A.V., Makarov, A.G., Stalevich, A.M. (2009) A version of modeling of nonlinear-hereditary viscoelasticity of polymer materials. Mechanics of Solids, Vol. 44, No 1, pp. 122-130. DOI: 10.3103/ S0025654409010130

Demidov, A.V., Makarov, A.G., Pereborova, N.V., Egorova, M.A. (2017) Forecasting of deformation-relaxation properties of poly amide fabric used to make the canopy. Izvestiya Vysshikh Uchebnykh Zavedenii, Seriya Teknologiya Tekstil'noi Promyshlennosti, Vol. 367, No 1, pp. 250-258. eid=2-s2.0-85033239149

Gorshkov, A.S. (2003) 75 years Soyuzteplostroi. Montazhnyei Spetsial'nye Raboty v Stroitel'stve, 9, pp. 15-19. eid=2-s2.0-0142041513

Gorshkov, A.S., Vatin, N.I. (2013a) Properties of the wall structures made of autoclaved cellular concrete products on the polyurethane foam adhesive. Magazine of Civil Engineering, Vol. 40, No 5, pp. 5-19. DOI: $10.5862 / \mathrm{MCE} .40 .1$

Gorshkov, A.S., Sokolov, N.A. (2013b) Inconsistency in Russian and international standards in the determination of the design values of thermal conductivity of building materials and products. Magazine of Civil Engineering, Vol. 42, No 7, pp. 7-14+78-80. DOI: 10.5862/MCE.42.2

Gorshkov, A.S., Makarov, A.G., Romanova, A.A., Rymkevich, P.P. (2013c) Modelling of directed polymers deformation processes based on the description of the kinetics of supramolecular structures separated by energy barriers. Magazine of Civil Engineering, Vol. 44, No 9, pp. 76-83+103-104. DOI: 10.5862/MCE.44.10

Gorshkov, A.S., Rymkevich, P.P., Vatin, N.I. (2014) Simulation of non-stationary heat transfer processes in autoclaved aerated concrete-walls. Magazine of Civil Engineering, Vol. 52, No 8, pp. 38-48 and 65-66. DOI: 10.5862/MCE.52.5 
Gorshkov, A.S., Rymkevich, P.P. (2015) A diagram method of describing the process of non-stationary heat transfer. Magazine of Civil Engineering, Vol. 60, No 8, pp. 68-82. DOI: 10.5862/MCE.60.8

Gorshkov, A.S., Vatin, N.I., Rymkevich, P.P., Kydrevich, O.O. (2018) Payback period of investments in energy saving. Magazine of Civil Engineering, Vol. 78, No 2, pp. 65-75. DOI: 10.18720/MCE.78.5

Grinfeldi, G.I., Gorshkov, A.S., Vatin, N.I. (2014) Tests results strength and thermophysical properties of aerated concrete block wall samples with the use of polyurethane adhesive. Advanced Materials Research, 941-944, pp. 786-799. DOI: 10.4028/www.scientific.net/AMR.941-944.786

Gryazev, M.V., Kachurin, N.M. and Vorob'ev, S.A. (2017) Mathematical models of gas-dynamic and thermophysical processes in underground coal mining at different stages of mine development. Journal of Mining Institute, 223, p. 99. DOI: 10.18454/pmi.2017.1.99.

Korniyenko, S.V., Vatin, N.I., Gorshkov, A.S. (2016) Thermophysical field testing of residential buildings made of autoclaved aerated concrete blocks. Magazine of Civil Engineering, Vol. 64, No 4, pp. 10-25. DOI: $10.5862 / \mathrm{MCE} .64 .2$

Lapshin, A. A. (2014) "Mathematical modeling of mine air conditioning in the zone of mine works", Journal of Mining Institute, 210, p. 53. Available at: http://pmi.spmi.ru/index.php/pmi/article/view/ 5265 (Accessed: 18 August 2020).

Leusheva, Ekaterina \& Morenov, Valentin \& Martel, A.S. (2019). Combined cooling heat and power supplying scheme for oil and gas fields development. 10.1201/9780429327070-53.

Makarov, A.G. (2002) Determining the analytical correlation between the standardized nuclei of relaxation and creep in textile materials. Izvestiya Vysshikh Uchebnykh Zavedenii, Seriya Teknologiya Tekstil'noi Promyshlennosti, Vol. 266, No 2, pp. 13-17. eid=2-s2.0-0036931214

Makarov, A.G., Pereborova, N.V., Egorova, M.A., Wagner, V.I. (2014a) Modeling and forecasting viscoelastic properties of textile materials with a complex structure. Izvestiya Vysshikh Uchebnykh Zavedenii, Seriya Teknologiya Tekstil'noi Promyshlennosti, Vol. 354, No 6, pp. 120-124. eid=2-s2.0 $-84937439497$

Makarov, A.G., Pereborova, N.V., Egorova, M.A., Wagner, M.A. (2014b) Ways of modeling deformation and relaxation properties of textile materials with a complex structure. Izvestiya Vysshikh Uchebnykh Zavedenii, Seriya Teknologiya Tekstil'noi Promyshlennosti, Vol. 351, No 3, pp. 110-115. eid=2-s2 $.0-84937410003$

Makarov, A.G., Demidov, A.V., Pereborova, N.V., Egorova, M.A. (2015a) Modeling and prediction of estimated relaxation and deformation properties of the polymer parachute line. Izvestiya Vysshikh Uchebnykh Zavedenii, Seriya Teknologiya Tekstil'noi Promyshlennosti, Vol. 360, No 6, pp. 194-205. eid=2-s2.0-84976560627

Makarov, A.G., Pereborova, N.V., Wagner, V.I., Vasileva, E.K. (2015b) Development of methodology for the comparative analysis of deformation and relaxation properties of aramid yarns and textile materials based on them. Izvestiya Vysshikh Uchebnykh Zavedenii, Seriya Teknologiya Tekstil'noi Promyshlennosti, Vol. 359, No 5, pp. 48-58. eid=2-s2.0-84971636036

Makarov, A.G., Slutsker, G.Y., Drobotun, N.V. (2015c) Creep and fracture kinetics of polymers. Technical Physics, Vol. 60, No 2, pp. 240-245. DOI: 10.1134/S1063784215020152

Makarov, A.G., Slutsker, G.Y., Gofman, I.V., Vasil'eva, V.V. (2016) Initial stage of stress relaxation in oriented polymers. Physics of the Solid State, Vol. 58, No 4, pp. 840-846. DOI: 10.1134/ S1063783416040132

Makarov, A.G., Pereborova, N.V., Egorova, M.A., Egorov, I.M. (2017a) Quality analysis of deformation-relaxation properties of aramid cords mountain rescue appointments. Izvestiya Vysshikh Uchebnykh Zavedenii, Seriya Teknologiya Tekstil'noi Promyshlennosti, Vol. 368, No 2, pp. 309-313. eid=2-s2.0-85035207042

Makarov, A.G., Pereborova, N.V., Egorova, M.A., Egorov, I.M. (2017b) Mathematical modeling of deformation-relaxation processes polymeric materials in conditions of variable temperatures. Izvestiya Vysshikh Uchebnykh Zavedenii, Seriya Teknologiya Tekstil'noi Promyshlennosti, Vol. 370, No 4, pp. 287-292. eid=2-s2.0-85057142312

Makarov, A.G., Pereborova, N.V., Vagner, V.I., Egorova, M.A., Klimova, N.S. (2018a) Spectral Analysis of Viscoelastic Creep of Geotextiles. Fibrie Chemistry, Vol. 50, No 4, pp. 378-382. DOI 10.1007/ s10692-019-09993-4

Makarov A.G., Pereborova N.V., Kozlov A.A., Shvankin A.M. (2018b) Computer-Assisted Prediction and Qualitative Analysis for Polymer Parachute Cords. Fibre Chemistry, Vol. 50, No. 3, pp. 239-242. DOI 10.1007/s10692-018-9968-1

Nikolaev, A \& Dokoukin, V \& Lykov, Yuri \& Fetisov, Vadym. (2018). Research of processes of heat exchange in horizontal pipeline. IOP Conference Series: Materials Science and Engineering. 327. 032041. 10.1088/1757-899X/327/3/032041. 
Pereborova N.V., Demidov A.V., Makarov A.G., Klimova N.S. (2018a) Modeling of DeformationRelaxation Processes of Aramid Textile Materials - the Foundation for Analyzing Their Operational Properties. Fibre Chemistry, Vol. 50, No. 2, pp. 104-107. DOI 10.1007/s10692-018-9941-z

Pereborova, N.V., Makarov, A.G., Egorova, M.A., Kozlov, A.A., Konovalov, A.S. (2018b) Methods of simulation and comparative analysis of shadow and deformation-reducing properties of aramide textile materials. Izvestiya Vysshikh Uchebnykh Zavedenii, Seriya Teknologiya Tekstil'noi Promyshlennosti, Vol. 375, No 3, pp. 253-257. eid=2-s2.0-85059766891

Pereborova, N.V., Makarov, A.G., Egorova, M.A., Klimova, N.S. (2018c) Methods of increasing the competitiveness of domestic aramid textile materials based on complex analysis of their functional properties. Izvestiya Vysshikh Uchebnykh Zavedenii, Seriya Teknologiya Tekstil'noi Promyshlennosti, Vol. 378, No 6, pp. 267-272. eid=2-s2.0-85072335464

Pereborova, N.V., Demidov, A.V., Makarov, A.G., Klimova, N.S., Vasileva, E.K. (2018d) Methods of mathematical modeling and qualitative analysis of relaxation-deformation processes of aramide textile materials. zvestiya Vysshikh Uchebnykh Zavedenii, Seriya Teknologiya Tekstil'noi Promyshlennosti, Vol. 374, No 2, pp. 251-255. eid=2-s2.0-85056451197

Pereborova, N.V., Makarov, A.G., Kozlov, A.A., Vasil'eva, E.K. (2018e) Development of Integral Optimality Criteria for Mathematical Modeling of Relaxation/Recovery Processes in Polymer Textile Materials. Fibrie Chemistry, Vol. 50, No 4, pp. 306-309. DOI 10.1007/s10692-019-09981-8

Pereborova N.V., Makarov A.G., Vasil'eva E.K., Shvankin A.M., Egorov I.M. (2019a) Mathematical Modeling and Computed Prediction of Viscoelastic Creep in Geotextile Nonwoven Fabrics. Fibre Chemistry, Vol. 50, No 6, pp. 487-490. DOI 10.1007/s10692-019-10015-6

Pereborova N.V., Makarov A.G., Egorova M.A., Klimova N.S. (2019b) Improving the Competitiveness of Aramid Textile Materials Based on Mathematical Modeling and Analysis of Their Performance Properties. Fibre Chemistry, Vol. 50, No 6, p. 569-572. DOI 10.1007/s10692-019-10030-7

Pereborova, N.V., Makarov, A.G., Egorova, M.A., Kozlov, A.A. (2019c) Mathematical Modeling and Comparative Analysis of Deformation/Recovery Properties and Shrinkage of Aramid Textile Materials. Fibre Chemistry, Vol. 50, No 5, pp. 468-472. DOI 10.1007/s10692-019-10010-x

Pereborova, N.V., Makarov, A.G., Shvankin, A.M., Egorova, M.A., Abramova, I.V. (2020a) Modeling and Qualitative Analysis of Creep Processes of Geotextile Nonwovens -A Foundation for Enhancing their Competitiveness. Fibre Chemistry, Vol. 51 No. 5, pp. 397-400. DOI 10.1007/s10692-020-10119-4

Pereborova, N.V., Makarov, A.G., Shvankin, A.M., Egorova, M.A., Korobovtseva, A.A. (2020b) Predicting Creep and Deformation and Recovery Processes of Geotextile Nonwovens. Fibre Chemistry, Vol. 51, No. 5, pp. 401-403. DOI 10.1007/s10692-020-10120-x

Pereborova, N.V., Makarov,A.G., Egorova,M.A., Egorov,I.M. (2020c) Methods of Modeling and Computer-Aided Prediction of Relaxation of Medical-Purpose Textile Elastomers. Fibre Chemistry, Vol. 51, No. 6, pp.467-470. DOI 10.1007/s10692-020-10136-3

Pereborova, N.V.,Makarov,A.G., Egorova,M.A., Egorov,I.M. (2020d) Methods modeling and Computer-Aided Prediction of Strain and Relaxation Processes of Medical-Purpose Textile Elastomers. Fibre Chemistry, Vol. 51, No. 6, pp.471-474. DOI 10.1007/s10692-020-10137-2

Perevoznikov, E.N., Gorshkov, A.S. (2004) Amplitude modulation mechanism of the free longitudinal vibrations in stressed filament yarns. Izvestiya Vysshikh Uchebnykh Zavedenii, Seriya Teknologiya Tekstil'noi Promyshlennosti, Vol. 280, No 5, pp. 73-76. eid=2-s2.0-19344363321

Romanova, A.A., Rymkevich, P.P., Gorshkov, A.S., Stalevich, A.M. (2005a) Dynamic relaxation of synthetic fibres. Khimicheskie Volokna, No 4, pp. 44 46. eid=2-s2.0-29144510616

Romanova, A.A., Rymkevich, P.P., Gorshkov, A.S., Stalevich, A.M. (2005b) Dynamic relaxation of synthetic fibres. Fibre Chemistry, Vol. 37, No 4, pp. 289-292. DOI: 10.1007/s10692-005-0097-2

Romanova, A.A., Rymkevich, P.P., Gorshkov, A.S., Stalevich, A.M. (2007) Young relaxing modulus of synthetic threads. Izvestiya Vysshikh Uchebnykh Zavedenii, Seriya Teknologiya Tekstil'noi Promyshlennosti, Vol. 299, No 4, pp. 3-5. eid=2-s2.0-36148930530

Rymkevich, P.P., Romanova, A.A., Golovina, V.V., Makarov, A.G. (2013) The energy barriers model for the physical description of the viscoelasticity of synthetic polymers: Application to the uniaxial orientational drawing of polyamide films. Journal of Macromolecular Science, Part B: Physics, Vol. 52, No 12, pp. 1829-1847. DOI: 10.1080/00222348.2013.808906

Stalevich, A.M., Makarov, A.G. (2000) Determining the inherent viscoelastic relaxation spectrum for synthetic filaments. Izvestiya Vysshikh Uchebnykh Zavedenii, Seriya Teknologiya Tekstil'noi Promyshlennosti, Vol. 255, No 3, pp. 8-12. eid=2-s2.0-0034436083

Stalevich, A.M., Makarov, A.G. (2002a) Forecasting the deformation recovery process and the reverse relaxation in polymer materials. Izvestiya Vysshikh Uchebnykh Zavedenii, Seriya Teknologiya Tekstil'noi Promyshlennosti, Vol. 268, No 4-5, pp. 15-18. eid=2-s2.0-0037742684 
Stalevich, A.M., Makarov, A.G., Saidov, E.D. (2002b) Elastic components in the stress/strain curve for a synthetic fibre yarn. IzvestiyaVysshikh Uchebnykh Zavedenii, Seriya Teknologiya Tekstil'noi Promyshlennosti, (4-5), pp. 15-18. eid=2-s2.0-0037742684

Stalevich, A.M., Makarov, A.G., Saidov, E.D. (2003) Relaxation spectrometry of synthetic yarns. Izvestiya Vysshikh Uchebnykh Zavedenii, Seriya Teknologiya Tekstil'noi Promyshlennosti, Vol. 270, No 1, pp. 16-22. eid=2-s2.0-2642532049

Vatin, N.I., Gorshkov, A.S., Nemova, D.V., Staritcyna, A.A., Tarasova, D.S. (2014) The energy-efficient heat insulation thickness for systems of hinged ventilated facades. Advanced Materials Research, 941944, pp. 905-920. DOI: 10.4028

Zimin, Z.S., Orlovich, R.B., Gorshkov, A.S. (2013) Application of stones of high voidage in the facing layer of the multilayer walls. Magazine of Civil Engineering, Vol. 43, No 8, pp. 14-23+77-78. DOI: 10.5862/MCE.43.3 